\title{
The Effects of Context-based Problem-solving Tasks on Students' Interest and Metacognitive Experiences
}

https://doi.org/10.1515/edu-2020-0118

received January 30, 2020; accepted June 29, 2020.

\begin{abstract}
Prior knowledge, motivational factors, and metacognition have been long considered basic elements for successful problem-solving process. However, the interplay of these variables with context-based task characteristics has rarely been explored in research. The present study aimed at investigating how context-based task characteristics influence these three elements, and further expands to explore potential differentiated effects across physics' topics. A multivariate analysis of covariance was conducted with 232 participants from high-track schools in Germany to investigate the effects of task characteristics and task topic with regard to their motivational and metacognitive variables. Overall results indicated that students' situational interest and estimate of solution correctness decrease through time as a result from their interaction with the tasks characteristics. Furthermore, between-subject factor analyses revealed important differences across the task topics of mechanics and thermodynamics. Finally, the covariate of prior knowledge was positively significant across all analyses. The findings demonstrate the importance of appropriate design of context-based tasks to positively influence students' motivation and metacognitive processing. Implications of the results, as well as further lines of research are discussed.
\end{abstract}

Keywords: context; problem-solving; task characteristics; task topic; interest; metacognitive experiences.

\footnotetext{
*Corresponding author: Marcela Pozas, Section for Teacher Education and Research, University of Trier, Trier, Germany, E-mail: pozas@uni-trier.de Patrick Löffler, Alexander Kauertz, Institute for Natural Sciences Education, Koblenz-Landau University, Landau, Germany Wolfgang Schnotz, Department of General and Educational Psychology, Koblenz-Landau University, Landau, Germany
}

\section{Introduction}

Worldwide, context-based learning has been acknowledged as an important instructional practice, particularly in science education (de Putter-Smits, Taconis \& Jochems, 2011; Kuhn \& Müller, 2014). Recent reviews have shown strong evidence to support the of use contextbased approaches for promoting students' positive attitudes in science (Bennett, Lubben \& Hogarth, 2007). Additionally, research has also pointed out at the benefits of context-based approaches on students' intrinsic motivation (Kuhn \& Müller, 2014) and interest (Löffler, Pozas \& Kauertz, 2018). Yet, cognitive factors (i.e. prior knowledge and skill) and motivation are not sufficient for successfully solving context-based problem-solving tasks. Metacognition is also considered as a basic requirement needed for working with problem-solving tasks in general (Jonassen, 2000; Mayer, 1998). Flavell (1979) referred to metacognition as the representation of cognition which is built on information from the monitoring function and informs the control function when cognition fails. Moore (1982) defines it as an individual's knowledge about their own thinking, while Gavelek and Raphael (1985) describe it as an individual's ability to accommodate their cognitive activity to foster effective comprehension. Overall, metacognition is considered as an individual's "characteristic that enables learners to regulate and make optimal choices with respect to their learning process" (Clarebout, Elen, Collazo, Lust, \& Jiang, 2013, p. 187). Flavell (1979) distinguished between three different facets of metacognition: metacognitive skills (activities such as planning, monitoring, and evaluation to control and regulate cognitive processes), metacognitive knowledge (e.g. knowledge of how to use information or specific strategies for a particular goal), and metacognitive experiences (awareness of cognitive processing) that can influence students' problem-solving performance (Clarebout et al. 2013; Efklides, 2001). The relationship between metacognition (and its facets) with learning and 
problem-solving in general has been long researched (Georghiades, 2004; Schoenfeld, 1992; Swanson, 1990), documenting the implications of metacognition when working with authentic or real-life problem solving tasks (Mayer, 1998; Neto \& Odete, 1997). A recent study by Gysin, Rehm, and Brovelli (2019) has shown that how an individual's knowledge is transfered within contextualized problem solving tasks might depend on the context itself and their metacognitive skills, more specifically, their use of metacognitive strategies.

To date, however, research on context-based problemsolving tasks has mainly focused on examining their effects on students' performance and motivation, overlooking the influential role of metacognition, and in particular, metacognitive experiences. Literature has continuously suggested that metacognitive experiences have an effect on cognition through metacognitive knowledge and control decisions regarding strategy use (Efklides, 2001; Efklides, 2008). Thus, they are an essential component of the regulation process that have an important impact on learning. In this vein, to fully understand the processes behind scientific modelling in context-based problemsolving, and in return, ensure students' meaningful learning, research needs to examine jointly all basic requirements for problem-solving (Jonassen, 2000; Mayer, 1998). Against this background, the primary goal of this study was to explore how physics' context-based task characteristics influence learners' characteristics such as situational interest and metacognitive experiences. According to Scott \& Berman (2013), a students' perception of difficulty of a domain may affect their motivation and metacognition, thus, the paper also seeks to explore potential differentiated effects across physics' topics.

\section{Theoretical Background}

\subsection{Context model}

Worldwide, educational curriculum reforms have focused on using contexts within science education as a mean to provide students with direct applicability of science content in their everyday life (Gilbert, 2006; Savelsberg et al., 2016). As discussed by research, such contexts can be classified based on two levels: the surface structure (problem situation) and the deep structure (scientific model) (Löffler et al., 2018; Mestre, 2002; van Vorst et al., 2014). Following this approach, Löffler and Kauertz (2016) established a context model that allows the identification of sets of information at the surface level and the deep level, and at the same time, pinpointing sets of information that link both levels together. These sets of information are dichotomously classified, on the one hand, as either elements of the scientific model (physics content) or elements that are not part of the scientific model (context), and on the other hand, as either part of the solution or not part of the solution (i.e. distracting elements). When all four sets of information are incorporated in a problem, then the solution process consists of (1) identifying the scientific model elements and non-scientific model elements that are part of the solution, (2) linking the non-scientific model elements with the scientific model elements (scientific model application), and lastly, (3) when needed, searching for relevant but missing scientific model elements that are not linked to the non-scientific model elements. This means that a scientific model needs to be developed (see figure 1).

From this framework, three task characteristics are identified:

- Contextualization refers to the presence of nonscientific model elements that are part of the solution and/or non-scientific model elements that are not part of the solution.

- Complexity refers to the number and interrelation of scientific model elements that are part of the solution inherently influencing task difficulty (Kauertz \& Fischer, 2006; Walpuski, Ropohl, \& Sumfleth, 2011)

- Transparency is characterized by either (1) the scientific model elements that are part of the solution explicitly specified within the task, or (2) if scientific model elements that are not part of the solution are included and therefore a differentiation between all sets of information is required for the solution, or (3) applying the scientific model is sufficient for solution, or (4), there needs to be a scientific model developed.

Even though contextualization and complexity are hierarchically measurable, this is not the case for transparency. Löffler et al. (2018) provide specific considerations: a task contains a high level of transparency, if it includes scientific model elements that are part of the solution in the absence of scientific model elements that are not part of the solution and therefore the learner does not need to differentiate among the elements. On the other hand, a low level of transparency would be when a learner needs to find the missing scientific model elements based on non-scientific model elements part of the solution while avoiding being misled by scientific model elements that are not part of the solution.

By using this context model as the guiding theoretical framework, it is possible to investigate the effects of the 


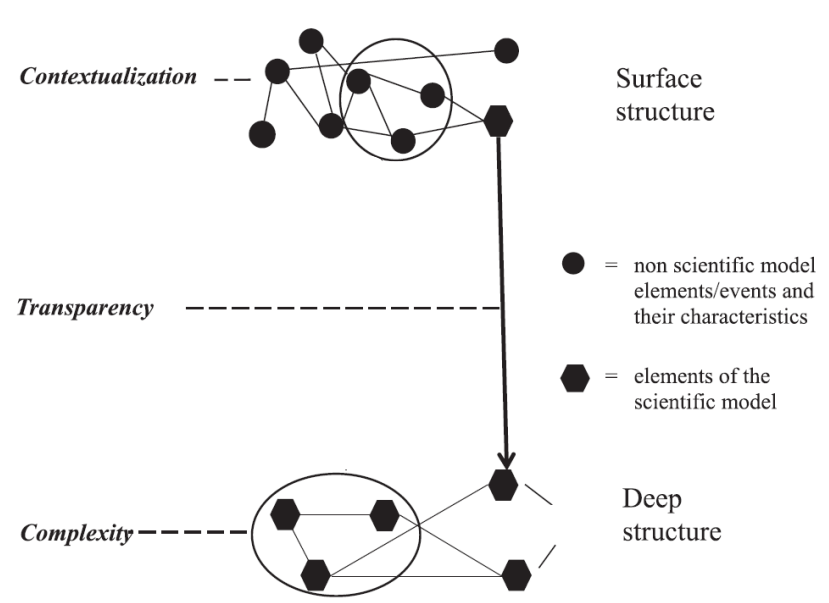

Figure 1: Context model according to Löffler \& Kauertz (2016a) with high contextualization, low transparency, and high complexity. The circled elements are necessary to solve the problem.

three task characteristics on students' situational interest and metacognitive experiences while solving contextbased tasks.

\subsection{Situational interest}

Depending on the theoretical orientation of the particular research, interest can be conceptualized in different ways (Krapp, Hidi \& Renninger, 1992). However, it is of common agreement that interest originates from a person's interaction with his or her environment (Krapp, 1999). Thus, interest is considered to be object-specific containing both affective and cognitive components that involve personal relevance and value, (Ryan \& Deci, 2000), and foster positive emotional experiences (Krapp, 2002; Krapp \& Prenzel, 2011).

Within the literature, two main conceptualizations have been suggested: (a) individual interest, and (b) situational interest. Individual interest refers to a stable affectiveevaluative pre-existing disposition to reengage with a particular subject, content, or object (Hidi, Renninger, \& Krapp, 2004), and commonly involves focused attention, persistence, and effort, as well as value-related attributes (Ainley, Hidi, \& Berndorff, 2002; Schiefele, 2009). In contrast, situational interest is a momentary emotional state resulting from the interaction with the 'interesting' content or situational factors (i.e. characteristics) of the learning task (Schiefele, 2009). This assumes that interest is within the individual, however, the content or situational factors define its direction and contribute to its development. Situational interest has been shown to
Table 1: Examples for the two levels of contextualization in a problem according to Löffler et al. (2018).

\begin{tabular}{|c|c|}
\hline $\begin{array}{l}\text { Level of } \\
\text { Contextualization }\end{array}$ & Problem Example \\
\hline Low & $\begin{array}{l}\text { Two devices have a power of } \mathrm{P} 1=2,5 \mathrm{~kW} \text { and } \\
\mathrm{P} 2=1,5 \mathrm{~kW} \text {. Calculate the current if the voltage } \\
\text { is } \mathrm{U}=230 \mathrm{~V} \text {. }\end{array}$ \\
\hline High & $\begin{array}{l}\text { Mr. Smith buys a radiant heater and a fan } \\
\text { heater for the changing table in his children's } \\
\text { room. Both devices advertise their large } \\
\text { electrical power }(2,5 \mathrm{~kW} \text { and } 1,5 \mathrm{~kW}) \text { and he } \\
\text { wonders whether the fuse }(16 \mathrm{~A}) \text { will blow if he } \\
\text { connects them to the same socket. }\end{array}$ \\
\hline
\end{tabular}

Table 2: Examples for the two levels of complexity in a problem according to Löffler et al. (2018).

\begin{tabular}{ll}
\hline Level of Complexity & Problem Example \\
\hline Low & $\begin{array}{l}\text { To prevent heat loss in cold conditions, birds } \\
\text { ruffle up their feathers to get air in between. } \\
\text { Explain why this is helpful. } \\
\text { A vacuum flask keeps coffee hot for a long } \\
\text { time. It is made up of two flasks: one placed } \\
\text { inside the other and jointed at the neck. The } \\
\text { gap between the flasks is evacuated of air. The } \\
\text { inner flask is covered with a reflecting layer. } \\
\text { Explain why this construction keeps coffee hot. }\end{array}$ \\
\hline
\end{tabular}

Table 3: Examples for the two levels of transparency in a problem according to Löffler et al. (2018).

\begin{tabular}{ll}
\hline $\begin{array}{l}\text { Level of } \\
\text { Transparency }\end{array}$ & Problem Example \\
\hline Low & $\begin{array}{l}\text { John jumps off the } 10 \mathrm{~m} \text { diving board. How fast } \\
\text { will he hit the water if his mass m equals } 65 \mathrm{~kg} ?\end{array}$ \\
High & $\begin{array}{l}\text { John jumps off the diving board (height } \mathrm{h}=10 \mathrm{~m}) . \\
\text { At what velocity v will he hit the water given that } \\
\text { the gravitational acceleration g equals } 9.81 \mathrm{~m} / \mathrm{s} 2 ?\end{array}$ \\
\hline
\end{tabular}

positively influence an individual's cognitive performance, to focus attention, to facilitate the integration of new knowledge, as well as to enhance the levels of learning (Hidi \& Renninger, 2006; Durik \& Harackiewicz, 2007). Additionally, research has linked interest to other variables such as effort, self-efficacy, goal setting, and self-regulated behaviour (Renninger \& Hidi, 2002; Hulleman, Godes, Hendricks, \& Harackiewicz, 2010).

Based on previous literature, Hidi (2000) proposed a two-phase model of situational interest: (1) triggered situational interest, and (2) maintained situational interest. A learner's situational interest could be triggered either by manipulating or by the features of task themselves, i.e. using perceptual features that can increase attention 
and arousal (Durik \& Harackiewicz, 2007). However, triggering situational interest does not inherently "hold" interest. Therefore, in order to maintain situational interest it is necessary to enhance the meaningfulness of the task at hand (Schiefele, 2009). Students are more likely to engage in materials and tasks they find meaning in, independent of whether they enjoy the overall content or not. Appropriate design and use of task characteristics should be novel, surprising, and stimulating in order to catch and maintain students' situational interest.

Results from a meta-analytic study by Savelsbergh et al. (2016), revealed that teaching approaches, such as context-based tasks, have overall positive significant effects on students' interest. For instance, findings by Vaino, Holbrook, and Rannikmäe (2012) indicated that when students participated and worked with contextbased tasks in chemistry, their interest developed positively. According to Walkington (2013), contexts activate interest while helping ground abstract ideas and their prior knowledge within concrete real-life experiences. Against this background, the present study focuses on examining the effect of task characteristics on student interest when working with different task topics. It focuses on both phases of triggered and maintained situational interest: the first measurement point will examine whether situational interest was triggered, while the second measurement point will assess whether situational interest was maintained throughout the task. Using this research design allows the examination of how the types of external support (i.e. task topic and characteristics) might contribute to the direction and development of situational interest in context-based problem-solving tasks.

\subsection{Metacognitive experiences}

Based on Flavell's (1979) theoretical framework of metacognition, Efklides (2001, 2009) states that metacognitive experiences "are influenced by the person, task and context characteristics and, despite their interrelations, each of them conveys different information about features of cognitive processing. Thus, they form the interface between the task and the person, and inform the person on his/her progress on task processing and the outcome produced" (p.7). Metacognitive experiences can take the form of metacognitive feelings such as the feeling of difficulty, the feeling of confidence, and the feeling of satisfaction. Such metacognitive feelings help the learner become aware of his/her processing with a specific task, and informs him/her whether there is a lack of fluency, obstacles, or conflicts experienced (Efklides, 2001). The feeling of difficulty for example, monitors cognitive processing, i.e., whether there is an error or lack of information in order to answer a task (Efklides, Papadaki, Papantoniou, \& Kiosseoglou, 1998). The feeling of difficulty gives cues to a learner on whether more effort needs to be invested in a task, invest more time on the task processing, or reexamine the answer provided. Overall, the feeling of difficulty results from a combination of different factors: (a) the task complexity, (b) cognitive ability (Efklides et al., 1998), (c) or whether the task is perceived as 'interesting' or 'difficult' (Efklides, 2006). As a learner works with a task, his or her initial feeling of difficulty ratings can significantly change because of the task processing. Therefore, the reported feeling of difficulty during, and after the task can be higher, similar, or lower than the initial measurement point (Efklides, 2006). In other words, if a learner encounters difficulty when answering a task, then it would be expected that their feeling of difficulty increases.

Other types of metacognitive experiences are metacognitive judgments such as: (a) the estimate of effort, which can be mainly influenced by a feeling of difficulty, (b) the estimate of solution correctness, which analyses whether the answer is correct or incorrect, (c) a feeling of confidence, informing whether the learner has confronted obstacles when providing an answer or not, and, (d) feeling of satisfaction, which monitors whether the answer provided meets the learner's quality criteria (Efklides, 2001; Efklides, 2006; Efklides, 2008). These judgements or estimates "monitor features of one's own cognition and one's experience with a task or stimulus" (Efklides, 2001, p. 301).

Considering that metacognitive experiences "refer to features of particular tasks" (Efklides, 2001, p. 300), metacognitive experiences can be influenced by task characteristics, task complexity, and conditions of task presentation. For instance, when a task's difficulty is high, the feeling of difficulty could increase while the feeling of confidence and satisfaction from the solution produced tend to decrease (Efklides, Samara, \& Petropoulou, 1999). This in return, inherently influences the resulting performance (Efklides, 2001; Frijda, 1986). For this reason, it is necessary to investigate the implications of contextbased task characteristics and task topic, and examine the conditions that positively influence metacognitive experiences functioning. 


\subsection{Task topic effects: differences across physics' topics}

Much has been discussed about the conceptual difficulties students come across when learning different physics' topics (Champagne \& Klopfer, 1979; Duprez \& Mehéut, 2003; Rosenblatt \& Heckler, 2011), yet less has been done to examine potential conceptual and structural differences across the topics that inherently influence students' motivation and metacognition. A recent study has attempted to explore variations across topics, revealing that some topics might be more transparent than others (Löffler \& Kauertz, 2014). These findings imply that there are indeed differences across physics' topics and student learning that should be further investigated in research. Consequently, it is necessary to conduct research on more than one topic simultaneously in order to examine comprehensively potential differences across topics.

\section{Research questions and hypotheses}

Based on the theoretical framework, the article seeks to explore the effects of context-based task characteristics and the task topic on students' situational interest and metacognitive experiences. Important to consider is that empirical research has examined jointly the effects of context-based problem-solving tasks cognitive on students' performance and motivation while overlooking the role of metacognition. Additionally, as discussed in the theoretical background, physics' topics are naturally different. For the purpose of this study, the topics of thermodynamics and mechanics have been selected given that both topics are expected to be covered within tenth grade high-track schools curricula. Against this background, the following hypotheses are considered:

- The task characteristic of contextualization triggers and sustains students' situational interest (Hidi; 2000), thus:

H1: Situational interested is stable (triggered and maintained) through time (within-subject factor) when working with highly contextualized tasks (between-subject factor).

- The task characteristics of complexity and transparency are related to the task's difficulty (Kauertz \& Fischer, 2006; Walpuski, Ropohl, \& Sumfleth, 2011), therefore:
H2: Students' feeling of difficulty and estimate of effort increases over time (within-subject factor) when working with low transparent and highly complex tasks (between-subject factor).

H3: Students' estimate of solution correctness increases over time (within-subject factor) when working with highly transparent and low complex tasks (betweensubject factor).

- There is little research done on the interplay of metacognitive experiences with different physics task topics such as thermodynamics and mechanics. Yet, there are some indications on possible structural differences between the topics (Löffler \& Kauertz, 2011), therefore:

H4: Students' feeling of difficulty and estimate of effort is higher in the topic of thermodynamics in comparison to the topic of mechanics (between-subject factor).

H5: Students' estimate of solution correctness is higher in the topic of mechanics in comparison to the topic of thermodynamics (between-subject factor).

H6: Students' feeling of confidence and satisfaction is higher in the topic of mechanics in comparison to the topic of thermodynamics (between-subject factor).

\section{Method}

\subsection{Participants and procedure}

The study follows an experimental design with a quantitative pre-post approach. Following convenient sampling (Creswell, 2012), $N=232$ tenth grade students from six high-track secondary schools (Gymnasium) in Germany participated in the study. Participants were $60 \%$ female and had a mean age of 15.26 years. Students were informed that they would be participating in a research project regarding physics topics, in which they would respond to tasks concerning thermodynamics and mechanics. Because their participation was voluntary and anonymous, they were also informed that their school grade would not be affected by their overall performance in these tasks. Students worked for 90 minutes on test booklets that were randomly assigned to them. Before answering the task, all necessary information and instructions were provided to the students. Students started by answering a prior knowledge assessment, then answered the first measurement point for the scales of interest, liking, and metacognitive experiences, continued by answering the task (either mechanics 
or a thermodynamics), and ended with the second measurement point for the scales of interest, liking, and metacognitive experiences. Due to test-time-constraints, no further data on socioeconomic status was collected.

\subsection{Instruments}

Context-based problem solving tasks. The tasks consisted on either a convection (thermodynamics) or a force (mechanics) problem situation to be solved. In addition, each of the tasks was varied with regard to the task characteristics of contextualization, complexity, and transparency (high or low). It is important to mention that both tasks had the same exact task characteristic variations, and therefore, would only differ in the task topic. In total, 16 tasks were administered, eight thermodynamic tasks and eight mechanics tasks (Löffler, 2016). The tasks used in the study described a convection (thermodynamics) and a force (mechanics) problem situation to be solved.

Concerning the task characteristics within the thermodynamics task, the highly contextualized versions described the discovery of a glacier mummy named "Ötzi" (Frozen Fritz). The contextualized variants contained an explanation concerning the mummy, artefacts, temperatures, and other images. On the other hand, the low contextualized versions presented a traditional textbook problem representation where detailed information regarding temperatures, symbols, and numbers were provided. Additionally, the highly transparent versions included physics concepts, terms, and measurements of heat, whereas in the low transparent versions, less scientific and more common daily life concepts were used.

Regarding the mechanics task, the highly contextualized versions compared two car crashes. The contextualized variants contained an explanation concerning the type of cars, the material they were made of, the crash itself, and the resulting damage to the cars. The low contextualized versions, on the other hand, presented the same force problem, but using a traditional textbook problem representation, which only included detailed information of objects, symbols, and numbers. Furthermore, the highly transparent versions made use of physics concepts, terms, and measurements of force, while in the low transparent versions, daily life concepts were used within the problem representation.

The task topics of mechanics and thermodynamics as well as the task characteristics of contextualization, complexity, and transparency were coded dichotomously (task topics as 0 and 1; task characteristics as high and low) in order to be able to use them in different statistical procedures.

Prior knowledge. Students' prior knowledge was measured using a 22-item physics' test stemming from the Institute for Educational Quality (Institut zur Qualitätsentwicklung im Bildungswesen) (IQB). The IQB is an academic institute that focuses on improving and assuring Germany's educational system quality. The 22 tests items ${ }^{1}$ were developed on the educational standards for primary schools and secondary level. The selected 22 items were identified and revised in order to ensure that they covered expected gymnasium tenth grade knowledge. Answers were marked as correct or incorrect; students received a point for every correct answer. A sum score for the total of the correct answers was calculated and used as a covariate in the analyses.

Metacognitive experiences. Students' metacognitive experiences were assessed twice, that is before and after working with the context-based task, using the Metacognitive Experiences Questionnaire (MEQ) (Efklides, 2002). The MEQ consists of two sets of items measuring students' prospective and retrospective (prepost) metacognitive experiences of feeling of difficulty ("How much difficulty do (did) you feel?"), estimate of effort ("How much effort do (did) you (need to) invest on the task?"), and estimate of solution correctness ("How correctly do you think you can (did you) solve this task?”). In addition, the MEQ includes two retrospective (post) items measuring students' feeling of confidence ("How confident are you that you correctly solved the task?") and feeling of satisfaction ("How satisfied are you with the task solution you provided?") after the problem-solving task was done. All answers were based on a 4-point scale, from $1=$ not at all to $4=$ very $m u c h$. Due to test-time-constraints, the use of long scales was not applicable for this study. Recent literature has indicated that the use of singleitem measures may represent acceptable alternatives to multiple-item scales (Diamantopoulos, Sarstedt, Fuchs, Wilczynski \& Kaiser, 2012; Gogol et al., 2014).

Interest. The MEQ (Dina \& Efklides, 2009; Efklides, 2002) has been expanded to include one item measuring interest ("How interesting is (was) the task?"). Interest was measured before and after working with the contextbased task. Response options were based on a 4-point scale, from $1=$ not at all to $4=$ very much .

1 Please refer to Wellnitz, Fischer, Kauertz, Mayer, Neumann, Pant, Sumfleth, and Walpuski (2012) for further information concerning the IQB physics' test construction and reliability. 
Table 4: Descriptive statistics.

\begin{tabular}{lllll}
\hline Variable & Median & $\boldsymbol{M}$ & SD & Range \\
\hline Task topic & .00 & .48 & .50 & $0-1$ \\
Contextualization & .00 & .48 & 50 & $0-1$ \\
Complexity & 1.00 & .52 & .50 & $0-1$ \\
Transparency & .50 & .50 & .50 & $0-1$ \\
Prior knowledge & 13.00 & 13.30 & 3.57 & $0-20$ \\
Pre-test interest & 3.00 & 2.81 & .82 & $1-4$ \\
Pre-test feeling of difficulty & 3.00 & 2.80 & .75 & $1-4$ \\
Pre-test estimate of effort & 3.00 & 2.93 & .78 & $1-4$ \\
Pre-test estimate of solution correctness & 3.00 & 2.58 & .76 & $1-4$ \\
Post-test interest & 3.00 & 2.51 & .93 & $1-4$ \\
Post-test feeling of difficulty & 3.00 & 2.94 & .79 & $1-4$ \\
Post-test estimate of effort & 3.00 & 2.96 & .77 & $1-4$ \\
Post-test estimate of solution correctness & 2.00 & 2.30 & .91 & $1-4$ \\
Feeling of confidence & 2.00 & 2.15 & .89 & $1-9$ \\
Feeling of satisfaction & 3.00 & 2.50 & .99 & $1-9$ \\
\hline
\end{tabular}

\subsection{Analyses}

In order to examine the research question, repeated measures MANCOVA was used. Multivariate analysis of variance has been selected instead of running multiple ANOVAs for several reasons (see also Field, 2009): (a) when conducting a considerable number of tests on the same data, there is a risk of inflating the familywise error rate; thus, by using MANOVAs, one is preventing the risk of making a Type I error, (b) because MANOVA includes all dependent variables in the same analysis, it takes into account the relationship between the outcome variables, and (c), MANOVA has greater power to identify an effect as it can detect whether groups vary along a combination of variables.

To be able to investigate the hypotheses $\mathrm{H} 1-\mathrm{H} 5$, a MANCOVA was conducted submitting time as a within-subject factor and task topic (mechanics or thermodynamics), contextualization (high or low), complexity (high or low), and transparency (high or low) as between-subject factors. Students' (self-reported) interest, feeling of difficulty, estimate of effort, and estimate of solution correctness were considered as dependent variables. In addition, prior knowledge was included in the analysis as a covariate.

Before the analyses were conducted, the following assumptions were checked for: (a) multivariate normality was revised by conducting Q-Q plots (Garson, 2012), which indicated that the dependent variables have multivariate normality within the groups, and (b), the assumption of homogeneity of covariance matrices was checked by using Box's test. Given that the Box' test is not significant and the assumption of multivariate normality is plausible, the Pillai's trace obtained from the analyses will be reported (Field, 2009). Of note, tests of sphericity were not conducted as MANCOVA does not require to fulfil this assumption (Field, 2009).

To explore the hypotheses H6, two separate analyses of covariance were conducted in order to include prior knowledge as a covariate. The first ANCOVA examined the effects of task topic and task characteristics on the dependent variable of the students' feeling of confidence, whereas the second ANCOVA investigated the effects of the students' feeling of satisfaction. The Levene's test of equality of error variance was not significant for both analyses, and therefore, homogeneity of variance could be assumed. In addition, two tests of the assumption of homogeneity of slopes revealed no significant interaction between prior knowledge and task topic and characteristics for both ANCOVAs. 


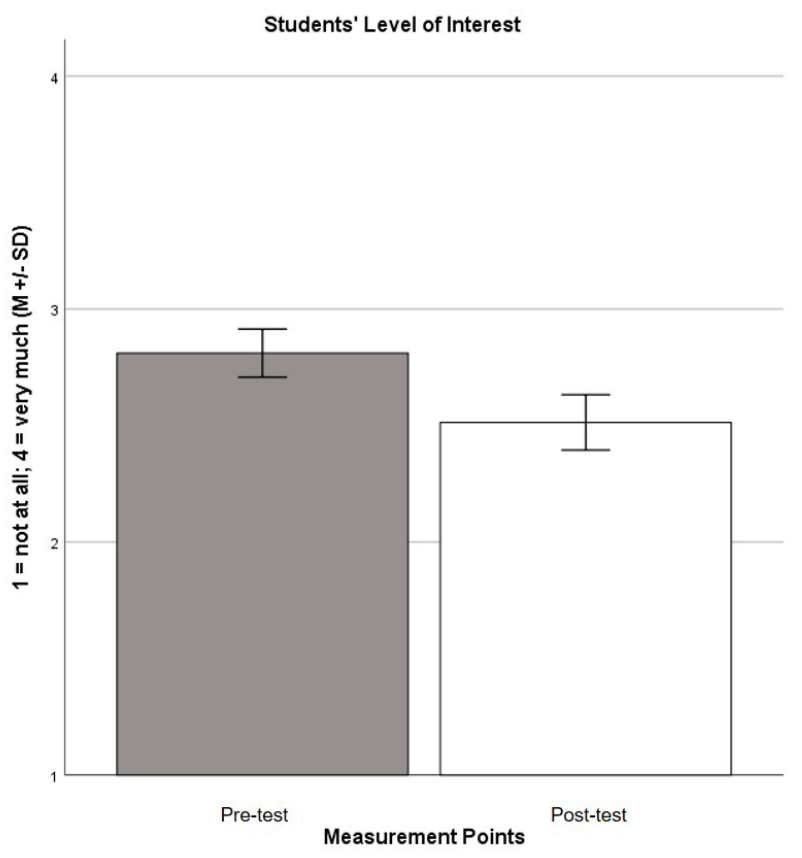

Figure 1a: Students' pre- and post-test levels of situation interest.

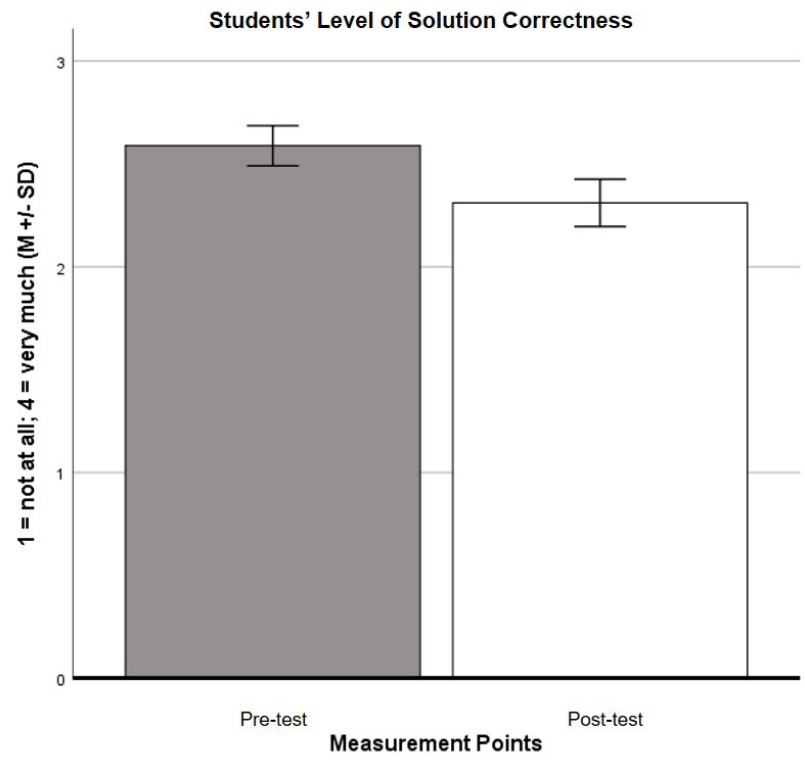

Figure 1b: Students' pre- and post-test levels of ESC.

\section{Results}

This section starts by presenting the descriptive statistics of the variables used in the study (table 1). Afterwards, the results for each set of hypotheses will be reported.
Effects of time, task topic, and task characteristics on students' interest, liking of the task, and metacognitive experiences (within-subject factors analyses). Using Pillai's trace, multivariate repeated measures analysis of covariance revealed a marginally significant main effect of time, $V=.04, F(4,205)=2.29$, $p<.10, \eta \mathrm{p}^{2}=.04$. Follow-up univariate analyses of each dependent variable found only a significant main effect for interest $\left(F(1,208)=7.34, p<.01, \eta \mathrm{p}^{2}=.03\right)$ and solution correctness $\left(F(1,208)=4.44, p<.05, \eta \mathrm{p}^{2}=.02\right)$. In detail, students' levels of interest (fig. 1a), and their solution correctness (fig. 1b) slightly drop through time.

Moreover, as indicated by Pillai's trace, multivariate repeated measures analysis of covariance reported a significant interaction effect of time, contextualization, and complexity, $V=.05, F(4,205)=2.65, p<.01, \eta p^{2}=.05$. Follow-up univariate analyses of each dependent variable found only a significant interaction effect for solution correctness $\left(F(1,208)=9.81, p<.01, \eta p^{2}=.05\right)$. As displayed in fig. 2a and fig. 2b, an interesting pattern of effects was found. Students' solution correctness ratings are shown to decrease through time when they are working with (1) a low contextualized and low complex task, (2) low contextualized and highly complex task, or (c) highly contextualized and highly complex task. On the other hand, students' solution correctness ratings remained relatively stable when working with a highly contextualized and low complex task.

Effects of task topic and task characteristics on students' interest, liking of the task, and metacognitive experiences (between-subject factor analyses). Using Pillai's trace, multivariate repeated measures analysis of covariance indicated a significant main effect of prior knowledge, $V=.12, F(4,205)=7.18, p<.001, \eta p^{2}=.12$. Follow-up univariate analyses of each dependent variable found a significant main effect of prior knowledge for all dependent variables: interest $(F(1,208)=8.41, p<.01$, $\left.\eta \mathrm{p}^{2}=.04\right)$, feeling of difficulty $(F(1,208)=11.48, p<.001$, $\left.\eta \mathrm{p}^{2}=.05\right)$, estimate of effort $(F(1,208)=16.59, p<.001$, $\left.\eta \mathrm{p}^{2}=.07\right)$, and solution correctness $(F(1,208)=20.34$, $p<.001, \eta \mathrm{p}^{2}=.09$ ). These results highlight the importance of prior knowledge on students' motivation, affect, and metacognitive processing.

Additionally, as indicated by Pillai's trace, multivariate repeated measures analysis of covariance found a significant interaction effect of task topic and contextualization, $V=.07, F(4,205)=3.80, p<.01, \eta p^{2}=.07$. Follow-up univariate analyses of each dependent variable found only a significant interaction effect for interest 


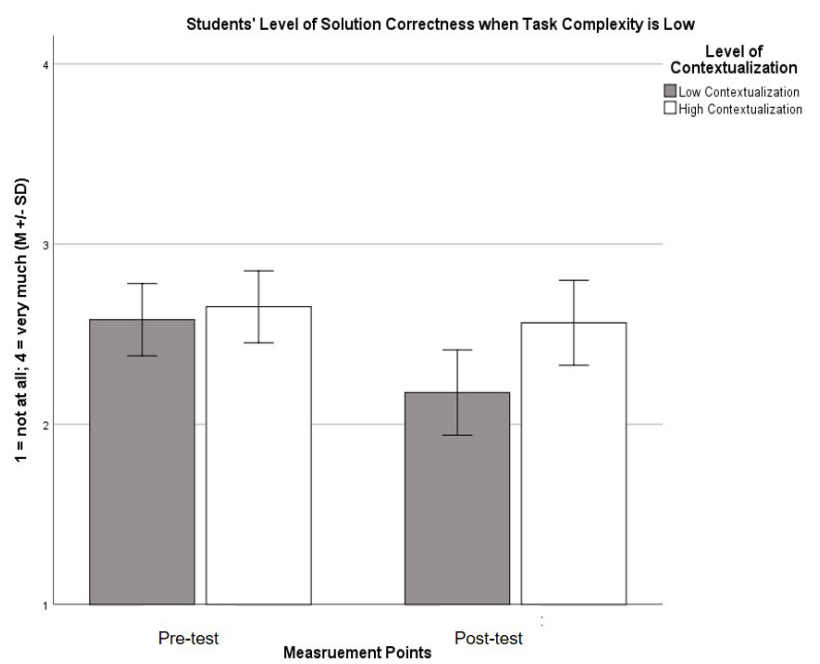

Figure 2a: Students' level of solution correctness: interaction effect of time, contextualization and complexity level (low complex task).

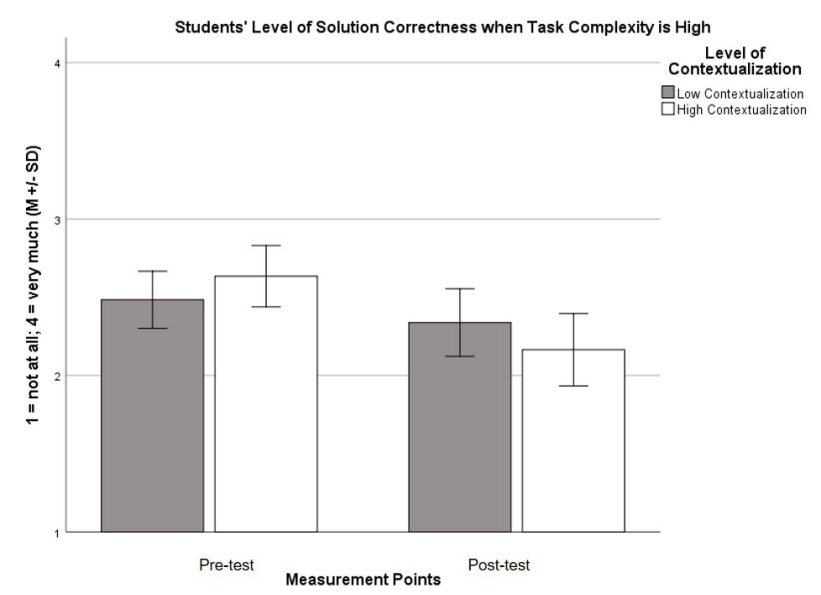

Figure 2b: Students' level of solution correctness: interaction effect of time, contextualization and complexity level (high complex task).

$\left(F(1,208)=9.36, p<.01, \eta p^{2}=.04\right)$. In detail, students reported higher levels of interest when working on a highly contextualized mechanics task, or when working with a low contextualized thermodynamics task (fig. 3).

Effects of task topic and task characteristics on students' feeling of confidence and satisfaction. Results from the first ANCOVA showed that prior knowledge covaried significantly with the dependent variable of students' feeling of confidence, $(F(1,212)=17.07, p<.001$, $\left.\eta \mathrm{p}^{2}=.10\right)$. However, there were no significant effects of the task topic or task characteristics on students' feeling of confidence.

On the other hand, results from the second ANCOVA revealed that prior knowledge covaried significantly with the dependent variable of students' feeling of satisfaction,

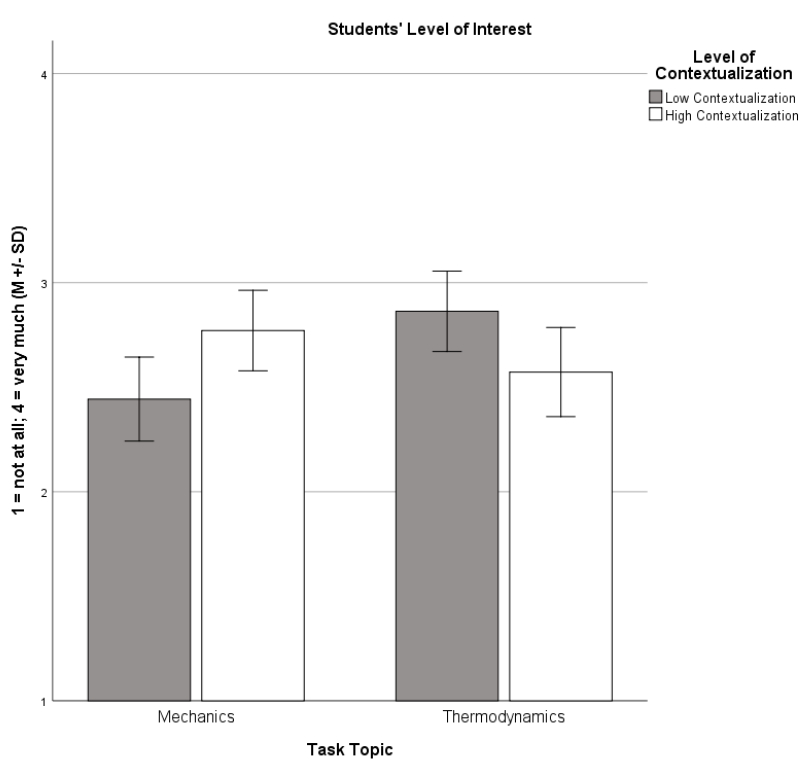

Figure 3: Students' level of situational interest: interaction effect of task topic and level of contextualization.

$\left(F(1,213)=16.68, p<.001, \eta p^{2}=.07\right)$. There was also a significant interaction effect of task topic, contextualization, and transparency on students' feeling of satisfaction after controlling for the effect of prior knowledge, $(F(1,213)$ $\left.=6.21, p<.05, \eta p^{2}=.03\right)$. In detail, results indicate that when working with a mechanics task, students feel more satisfied with their solution if such task has: (a) both a low contextualization and low transparency, or (b) both a high contextualization and high transparency (fig. 4a). In contrast, when working with a thermodynamics task, students feel more satisfied with their solution if such task has: (a) a high contextualization but low transparency, or (b) low contextualization and high transparency (fig. 4b).

\section{Discussion}

In the following section, each of the hypotheses will be discussed in detail.

H1: Situational interested is stable (triggered and maintained) through time (within-subject factor) when working with highly contextualized tasks (betweensubject factor).

Overall, for both task topics, the within-subject factor analyses revealed that interest slightly drops through time; therefore, $\mathrm{H} 1$ has to be rejected. This appears surprising as literature has argued that context-based tasks can positively influence interest (Hickey, 1997; Schiefele, 2009) and previous findings following the same research design 


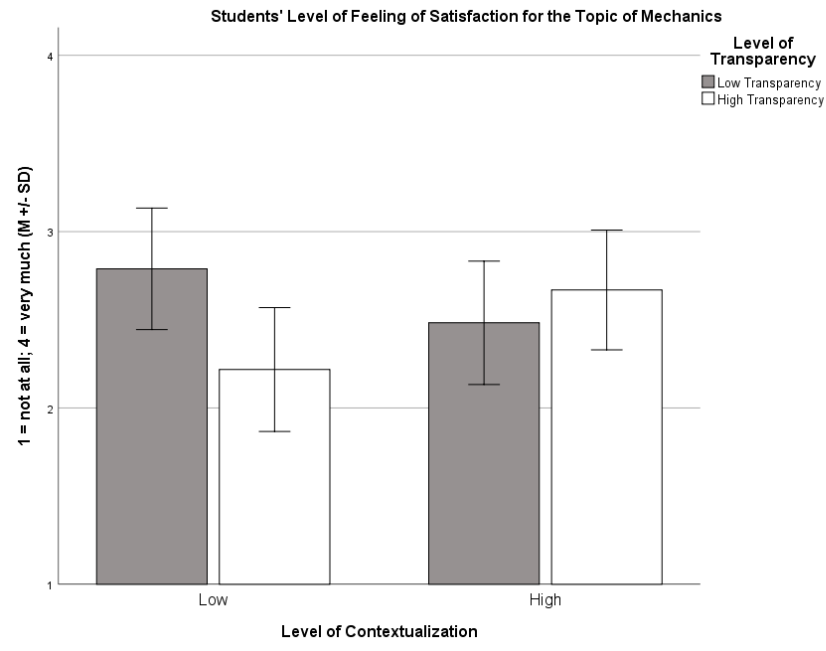

Figure 4a: Students' feeling of satisfaction for the task topic of Mechanics.

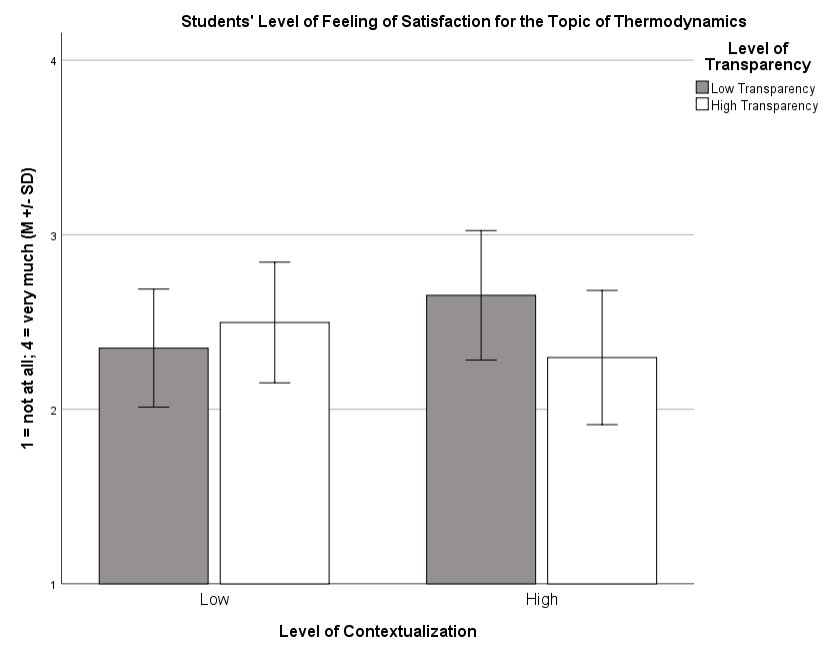

Figure 4b: Students' feeling of satisfaction for the task topic of Thermodynamics.

drew opposite results (see Löffler et al., 2018). However, recent research on context-based problem-solving tasks has yield mixed results (Rellensmann \& Schukajlow, 2017). Whereas some studies indicate that levels of situational interest actually increase after working with context-based tasks (Tapola, Veermans, \& Niemivirta, 2013), others report no significant difference between traditional and context-based tasks (Schukajlow et al., 2012), or as in this case, lower levels of situational interest (Rellensmann \& Schukajlow, 2017). These heterogeneous results could be the due to the fact that a large amount of situational interest research has been carried out using numerous instruments of diverse nature (Savelsberg et al., 2016; Schiefele, 2009).
Also interesting are the results from the between-subject factor analyses, which revealed an unexpected interaction effect between task topic and level of contextualization. It appears that students' level of situational interest is higher when working with a highly contextualized mechanics task, or when working with a low contextualized thermodynamics task. These results clearly indicate a topic effect that could be resulting from the different underlying complexity and abstractness of the structure, principles, and concepts of mechanics and thermodynamics. That is, a highly contextualized task does not hold the same effects across all physics topics. On the contrary, depending on the task topic, the level of contextualization can either foster or hinder students' interest. Such a result highlights the necessity for teachers to be aware of how to design appropriately context-based problem-solving tasks that ensure supporting and contributing to students' interest and all other variables associated to it.

H2: Students' feeling of difficulty and estimate of effort increases over time (within-subject factor) when working with low transparent and highly complex tasks (between-subject factor).

The combination of low transparency and high complexity was expected to increase students' feeling of difficulty, and thus their estimate of effort. However, MANCOVA analyses showed no significant effects. In consequence, $\mathrm{H} 2$ must be rejected. These results, although not expected, are still consistent with literature. Efklides (2006) has argued that the feeling of difficulty can be continuously updated throughout the task processing, and as such, the feeling of difficulty can be higher, lower, or even remain the same as the initial reported value. Thus, it could be assumed that students did not experience significant changes that would prompt them to revise their metacognitive experiences and exert control decisions. Furthermore, as feeling of difficulty and estimate of effort are both interrelated, it is not surprising that no effects for estimate of effort were also reported (Akama, 2006; Efklides, 2006; Efklides, Samara, \& Petropoulou, 1999). However, important to note is that when examining the mean and median values reported for the feeling of difficulty and the estimate of effort (table 1) it clearly appears that students rated high in the feeling of difficulty and the estimate of effort. Thus, it can be suggested that students perceived the tasks as hard.

H3: Students' estimate of solution correctness increases over time (within-subject factor) when working with highly transparent and low complex tasks (betweensubject factor).

Results from the within-subject factor MANCOVA revealed an overall decrease of students' solution 
correctness. No interaction effects of high transparency and low complexity on students' solution correctness were reported. Instead, an interaction effect of time, contextualization, and complexity was shown, thus $\mathrm{H} 3$ has to be partially rejected. Students' solution correctness ratings are maintained when working with highly contextualized and low complex tasks. This indicates that indeed a low complex task is perceived as easier, however, only when an interesting context is included. Previous literature has linked solution correctness to a learner's cognitive ability, motivation, and affect (Efklides, 2006). In this vein, the combination of the task characteristics of high contextualization and low complexity could positively assist students by supporting their interest and positive affect (e.g. liking of the task). A correlation analysis confirms this explanation, revealing a large correlation of $r=.46$, $p<.001$ between students' post-test reported situational interest and solution correctness. It is strongly suggested that further research comprehensively investigates how the design and combination of task characteristics influences metacognitive experiences and their interrelations with motivation and positive/negative affect.

H4: Students' feeling of difficulty and estimate of effort is higher in the topic of thermodynamics in comparison to the topic of mechanics (between-subject factor).

H5: Students' estimate of solution correctness is higher in the topic of mechanics in comparison to the topic of thermodynamics (between-subject factor).

No significant task topic effects were found for students' feeling of difficulty, estimate of effort and solution correctness, therefore, $\mathrm{H} 4$ and $\mathrm{H} 5$ must be rejected. Efklides et al. (1999) have argued that, although the feeling of difficulty is related to task difficulty, the feeling of difficulty is a complex experience that cannot function as a reflection of a tasks' difficulty as it is influenced by personal characteristics such as cognitive abilities, prior knowledge, and affect (Efklides, 2006; Efklides, Papadaki, Papantoniou, \& Kiosseoglou, 1998; Efklides et al., 1999). Moreover, solution correctness has also been linked to prior knowledge (Costermans, Lories, \& Ansay, 1992). Findings from the between-subject factors MANCOVA revealed that students' prior knowledge was a significant positive covariate on their metacognitive experiences. Accordingly, it could be argued that students' prior knowledge is serving as an important coping variable helping students manage their feeling of difficulty, estimate of effort, and solution correctness in both thermodynamics' and mechanics' tasks.

H6: Students' feeling of confidence and satisfaction is higher in the topic of mechanics in comparison to the topic of thermodynamics (between-subject factor).
With regard to students' feeling of confidence, ANCOVA revealed no significant effects. Because the feeling of confidence is related to the outcome of processing, it is linked to the feeling of difficulty (Efklides, 2009). Consequently, if the task topic did not exert significant influences on students' feeling of difficulty, it can be assumed that there would also not be effects on their feeling of confidence. In contrast to feeling of confidence, ANCOVA did showed significant effects for students' feeling of satisfaction. Nonetheless, these effects are not solely due to the task topic, but are produced by an interaction effect of task topic, contextualization, and transparency. Concerning mechanics, it appears that students' feeling of satisfaction is higher when working with either a highly contextualized and transparent task or with a low contextualized and transparent task, whereas in thermodynamics, higher levels of feeling of satisfaction are only reported for a highly contextualized but low transparent task or low contextualized and highly transparent tasks. The findings highlight that how task characteristics are combined within a specific topic support or hinder whether students are able to understand the task, identify the relevant solution elements, and provide an acceptable answer that meets the goals for the particular task. In other words, whether the outcome of the task is in line with the standard and quality criteria set by the learner.

\section{Conclusions, Limitations, and Further Research}

While previous research has argued that context-based approaches positively influences students' motivation and learning (Bennett, Lubben, \& Hogarth, 2007; Kuhn \& Müller, 2014), the potential effects of context-based tasks on students' metacognition have been long overlooked. Additionally, despite the importance of the interplay of prior knowledge, motivation, and metacognition in problem-solving processes (Jonassen, 2000; Mayer, 1998), these three elements have normally been isolated in context-based research. The present paper attempts to further these interactions. By examining students' situational interest and metacognitive experiences (while controlling for prior knowledge) when working with a context-based task, this paper has shown that contextbased task characteristics do indeed influence learners' characteristics significantly, in both positive and negative directions. Furthermore, this paper expands its scope by considering potential differentiated effects across topics. 
This study holds both theoretical and practical implications. From the theoretical perspective, the findings from this work contribute empirical evidence to the ongoing research on the interplay of task characteristics and learner characteristics, support the growing research on metacognitive experiences functioning (Boekaerts, 1999), and provide an initial insight into the different underlying structures of physics' topics. From a practical perspective, this research recognizes the importance of the appropriate design and use of context-based task characteristics in order to ensure students' successful and meaningful learning of the different physics' topics. Additionally, it highlights the necessity for teachers to be trained in how to correctly design and develop contextbased tasks.

The present study represents an initial step in presenting empirical data on the interplay of learner's characteristics, task characteristics, and task topic; however it is not without limitations. This paper investigates the physics' topics of thermodynamics and mechanics, thus, it is not possible to claim that a similar pattern of results will occur with other physics' topics. Because each of the topics is naturally different, future research should attempt to expand, investigate, and compare other physics' topics such as electricity and optics in order to map clearly all possible patterns of effects. It must be noted that this study used only two specific tasks (Frozen Fritz and a car crash). Thus, it is not possible to generalize the results from these two context examples into other thermodynamics or mechanics context-based problem solving tasks. Further research is necessary to comprehensively investigate and compare similar or differential effects within a wider range of tasks within each of these topics. Nonetheless, the results from the present study can be informative for other physics problems, topics, and range of tasks within each topic.

This paper addresses the interplay of prior knowledge, situational interest, and metacognitive experiences, but students' performance was not incorporated into the analyses. Hence, it is not possible to provide any type of assumptions on whether students' performance could be influenced by the interplay of variables being studied. In this area, further research is strongly encouraged to include measurements of performance in order to build a complete model of influences and effects.

Additionally, some of the hypotheses were investigated in an explorative manner (i.e. differences across task topics), therefore, as stated before, further research is needed to comprehensively examined how the design and combination of task characteristics influences metacognitive experiences, their interrelations with cognitive ability, motivation and positive/negative affect, as well as with overall performance.

Lastly, it is also necessary to discuss the surprising results on situational interest. In order to clarify the mixed effects of contextualization on students' situational interest, it is strongly suggested that further research makes use of more direct measures of situation interest that are theoretically bound to the existing theories on the nature of situational interest (Schiefele, 2009). Only by doing so will it be possible to clearly understand contextbased task characteristics' effects on the catch and hold mechanism of situational interest.

In summary, this study provided initial insights into the complex interaction of learner's characteristics and task characteristics, allowing us to map the complex pattern of effects across different task topics. The findings demonstrate the importance of not isolating learners' characteristics in research, but on the contrary, to explore them linked together.

Disclosure statement: No potential conflict of interest was reported by the authors.

Funding: This work was supported by Deutsche Forschungsgemeinschaft: [Grant Number GRK 1561].

\section{References}

Ainley, M., Hidi, S., \& Berndorff, D. (1999). Situational and individual interest in cognitive and affective aspects of learning. Paper presented at the American Educational Research Association Meetings, Montreal, Quebec, Canada.

Ainley, M., Hidi, S., \& Berndorff, D. (2002). Interest, Learning, and the Psychological Processes That Mediate Their Relationship. Journal of Educational Psychology, 94(3), 545-561.

Angell, C., Guttersrud, Ø., Henriksen, E. K. \& Isnes, A. (2004). Physics: Frightful, but fun. Pupils' and teachers' views of physics and physics teaching. Science Education, 88(5), 683706. https://doi.org/10.1002/sce.10141

Bennett, J., Lubben, F., \& Hogarth, S. (2007). Bringing Science to Life: A Synthesis of the Research Evidence on the Effects of Context-Based and STS Approaches to Science Teaching. Science Education, 91(3), 347-370.

Boekaerts, M. (1999). Metacognitive experiences and motivational state as aspects of self-awareness: Review and discussion. European Journal of Psychology and Education, 14(4), 571-584. Brophy, J. (2010). Motivating students to learn. New York: Routledge. Champagne, A., \& Klopfer, L. (1979). Interpretations of observations of motion and semantic knowledge structures of students at four grade levels. Annual Meeting of the national Association for Research in Science Teaching, 3-57.

Clarebout, G., Elen, J., Collazo, N.A., Lust, G., \& Jiang, L. (2013). Metacognition and the use of tools, in R. Azevedo \& V. Aleven 
(Eds.), International Handbook of Metacognition and Learning Technologies, 28. https://doi.org/ 10.1007/978-1-4419-55463_13

Costermans, J., Lories, G., \& Ansay, C. (1992). Confidence Level and Feeling of Knowing in Question Answering: The Weight of Inferential Processes. Journal of Experimental Psychology, 18(1), 142-150.

Diamantopoulos, A., Sarstedt, M., Fuchs, C., Wilczynski, P., \& Kaiser, S. (2012). Guidelines for choosing between multi-item and single-item scales for construct measurement: A predictive validity perspective. Journal of the Academic Marketing Science, 40, 434-449.

Dina, F., \& Efklides, A. (2009). Student profiles of achievement goals, goal instructions and external feedback: Their effect on mathematical task performance and affect. European Journal of Education and Psychology, 2(3), 235-262.

Duprez, C., \& Méheut, M. (2003). About some of the difficulties in learning thermodynamics at the university level. Science Education Research in the Knowledge-Based Society, 99-106.

Durik, A., \& Harackiewicz, J. (2007). Different strokes for different folks: How individual interest moderates the effects of situational factors on task interest. Journal of Educational Psychology, 99(3), 597-610.

Efklides, A. (2001). Metacognitive Experiences in Problem Solving: Metacognition, Motivation, and Self-Regulation. In A. Efklides, J. Kuhl, \& R. M. Sorrentino (Eds.), Trends and prospects in motivation research (Vol. 84, pp. 297-323). Dordrecht, London: Kluwer Academic. https://doi.org/10.1007/0-306-47676-2_16

Efklides, A. (2002). The systemic nature of metacognitive experiences: Feelings, judgments, and their interrelations. In M. Izaute, P. Chambres, \& P. J. Marescaux (Eds.), Metacognition: Process, function, and use (pp. 19-34). Dordrecht, The Netherlands: Kluwer Academic.

Efklides, A. (2006). Metacognition and affect: What can metacognitive experiences tell us about the learning process? Educational Research Review, 1, 3-14.

Efklides, A. (2008). Metacognition: defining its facets and levels of functioning in relation to self-regulation and co-regulation. Educational Psychologist, 13(4), 277-287.

Efklides, A. (2009). The role of metacognitive experiences in the learning process. Psicotherma, 21(1), 76-82.

Efklides, A., Papadaki, M., Papantoniou, G., \& Kiosseoglou, G. (1998). Individual differences in feelings of difficulty: The case of school mathematics. European Journal of Psychology of Education, 13(2), 207-226. https://doi.org/10.1007/ BF03173090

Efklides, A., Samara, A., \& Petropoulou, M. (1999). Feeling of difficulty: An aspect of monitoring that influences control. European Journal of Psychology and Education, 14(4), 461-476.

Field, A. P. (2009). Discovering statistics using SPSS: (and sex and drugs and rock ' $n$ ' roll). London, UK: SAGE Publications.

Flavell, J. H. (1979). Metacognition and Cognitive Monitoring - A New Area of Cognitive-Developmental Inquiry. American Psychologist, 34(10), 906-911.

Frijda, N. H. (1986). Studies in emotion and social interaction. The emotions. New York: Cambridge University Press.

Garson, G. D. (2012). Testing Statistical Assumptions. Asheboro, NC: Statistical Associates Publishing.
Georghiades, P. (2004). From the general to the situated: three decades of metacognition. International Journal of Science Education, 26(3), 365-383.

Gilbert, J.K. (2006). On the nature of "context" in chemical education. International Journal of Science Education, 28, 957-976.

Gogol, K., Brunner, M., Goetz, T., Martin, R., Ugen, S., Keller, U., .. . Preckel, F. (2014). "My Questionnaire is Too Long!” The assessments of motivational-affective constructs with threeitem and single-item measures. Contemporary Educational Psychology, 39(3), 188-205.

Gravelek, J.R. \& Raphael, T.E. (1985). Metacognition, instruction, and questioning, in D.L. Forrest-Pressley, G.E. Mackinnon \& T.G. Waller (Eds.) Metacognition, Cognition, and Human Performance. Vol. 2: Instructional Practices. Orlando: Academic Press.

Gysin, D., Rehm, M., \& Brovelli, D. (2019). Knowledge coordination and the use of context during the transfer process in physics. European Science Education Research Association, Bologna, Italy. https://www.phlu.ch/_Resources/Persistent/9e71e409 21e1721a288d2d045570cd6c37317dd7/ESERA\%202019\%20 Physik.pdf

Hickey, D. T. (1997). Motivation and Contemporary SocioConstructivist Instructional Perspectives. Educational Psychologist, 32(3), 175-193.

Hidi, S. (2000). An interest researcher's perspective: The effects of extrinsic and intrinsic factors on motivation. In C. Sansone \& J. M. Harackiewicz (Eds.), Intrinsic and extrinsic motivation: The search for optimal motivation and performance (pp. 309-339). San Diego, CA: Academic Press.

Hidi, S., \& Harackiewicz, J. M. (2000). Motivating the academically unmotivated: A critical issue for the 21st century. Review of Educational Research, 70, 151-179.

Hidi, S., Renninger, A., \& Krapp, A. (2004). Interest, a motivational variable that combines affective and cognitive functioning. In D. Dai \& R. Sternberg (Eds.), Motivation, emotion, and cognition (pp. 89-115). Mahwah, NJ: Lawrence Erlbaum Associates, Inc.

Hidi, S., \& Renninger, A. (2006). The four-phase model of interest development. Educational Psychologist, 41(2), 111-127.

Hullemann, C. S., Godes, O., Hendricks, B. L., \& Harackiewicz, J. M. (2010). Enhancing Interest and Performance with a Utility Value Intervention. Journal of Educational

Jonassen, D. H. (2000). Toward a Design Theory of Problem Solving. Educational Technology Research and Development, 48(4), 63-85.

Kauertz, A., \& Fischer, H. E. (2006). Assessing students' level of knowledge and analysing the reasons for learning difficulties in physics by rasch analysis. In W.J. Boone $\& X$. Liu. Applications of Rasch measurement in science education (pp. 212-246).

Krapp, A. (1999). Interest, motivation and learning: An educationalpsychological perspective. European Journal of Psychology and Education, 14(1), 23-40.

Krapp, A. (2002). Structural and dynamic aspects of interest development: theoretical considerations from an ontogenetic perspective. Learning and Instruction, 12, 383-409.

Krapp, A., Hidi, S., \& Renninger, K. A. (1992). Interest, learning, and development. In K.A. Renninger, S. Hidi, \& A. Krapp (eds.), The role of interest in learning and development (pp. 3-25). 
Krapp, A., \& Prenzel, M. (2011). Research on interest in science: Theories, methods, and findings. International Journal of Science Education, 33, 27-50.

Kuhn, J., \& Müller, A. (2014). Context-based science education by newspaper story problems: A study on motivation and learning effects. Perspectives in Science, 2, 5-21.

Löffler, P. (2016). Modellanwendung in Problemlöseaufgaben - Wie wirkt Kontext? Studien zum Physik- und Chemielernen: Vol. 205. Berlin: Logos Berlin.

Löffler, P., \& Kauertz, A. (2014). Applying physics models in contextbased tasks in physics education. In: C. Constantinou, N. Papadouris, \& A. Hadjigeorgiou (Hrsg.), E-Book Proceedings of the ESERA 2013 Conference: Science Education Research For Evidence-based Teaching and Coherence in Learning - Nikosia, Zypern 2014, (Strand 10, pp. 171-179).

Löffler, P., \& Kauertz, A. (2016). Modellanwendung in Problemlöseaufgaben: Wie wirkt Kontext? [Model use in problem-solving tasks: how does a context work?] In C. Maurer, Authentizität und Lernen - das Fach in der Fachdidaktik. GDCP, Jahrestagung in Berlin 2015 (Vol. 36, pp. 41-43).

Löffler, P., Pozas, M., \& Kauertz, A. (2018). How do students coordinate context-based information and elements of their own knowledge? An analysis of students' context-based problem-solving in thermodynamics. International Journal of Science Education, 40(16), 1935-1956. https://doi.org/10.1080 /09500693.2018.1514673

Mayer, R. (1998). Cognitive, metacognitive, and motivational aspects of problem-solving. Instructional Science, 26(1/2), 49-63.

Mestre, J. (2002). Probing adults' conceptual understanding and transfer of learning via problem posing. Journal of Applied Developmental Psychology, 23(1), 9-50.

Moore, T. (1982). Understanding Language. London: Macmillian.

Neto, A. J., \& Odete Valente, M. (1997). Problem Solving in Physics: Towards a Synergetic Metacognitively Developed Approach. National Association for Research in Science Teaching, 3-30.

Pintrich, P. R. (2003). A Motivational Science Perspective on the Role of Student Motivation in Learning and Teaching Contexts. Journal of Educational Psychology, 95(4), 667-686.

Putter-Smits, L.G.A. de, Taconis, R., \& Jochems, W.M.G. (2011). De emphasisvoorkeur van docenten biologie, natuurkunde en scheikundeen de gevolgen voor curriculumvernieuwingen [The emphasis preference of biology, physics and chemistry teachers and the consequences for curriculum innovations]. Tijdschrift voor Didactiek der b-wetenschappen, 28(1), 33-48.

Renninger, A., \& Hidi, S. (2002). Student interest and achievement: Developmental issues raised by a case study. In A. Wigfield \& J. S. Eccles (Eds.), Development of achievement motivation (pp. 173-195). New York: Academic.

Rosenblatt, R., \& Heckler, A. F. (2011). Systematic study of student understanding of the relationship between the directions of force, velocity, and acceleration in one dimension. Physical Review Special Topics - Physics Education Research, 7, 1-20.

Ryan, R., \& Deci, E. (2000). Self-determination theory and the facilitation of intrinsic motivation, social development, and well-being. American Psychologist, 55(1), 68-78.

Savelsberg, E.R., Prins, G.T., Reitbergen, C., Fechner, S., Vaessen, B.E., Draijer, J.M., \& Bakker, A. (2016). Effects of innovative science and mathematics teaching on student attitudes and achievement: A meta-analytic study. Educational
Research Review, 19, 158-172. http://dx.doi.org/10.1016/j. edurev.2016.07.003

Schiefele, U. (2009). Situational and Individual Interest. In K. R. Wentzel \& A. Wigfield (Eds.), Handbook of Motivation at School (pp. 197-222). New York: Taylor and Francis.

Schoenfeld, A. H. (1992). Learning to think mathematically: Problem solving, metacognition, and sense-making in mathematics. In D. Grouws (Ed.), Handbook for Research on Mathematics Teaching and Learning (pp. 334-370). New York: MacMillan.

Schukajlow, S., Leiss, D., Pekrun, R., Blum, W., Müller, M., \& Messner, R. (2012). Teaching methods for modelling problems and students' task-specific enjoyment, value, interest and self-efficacy expectations. Educational Studies in Mathematics, 79(2), 215-237.

Schukajlow, S., Rellensmann, J. (2017). Does students' interest in a mathematical problem depend on the problem's connection to reality? An analysis of students' interest and pre-service teachers' judgments of students' interest in problems with and without a connection to reality. ZDM Mathematics Education, 49, 367-378.

Scott, B., \& Berman, A. (2013). Examining the domain-specificity of metacognition using academic domains and task-specific individual differences. Australian Journal of Educational \& Developmental Psychology, 13, 28-43.

Swanson, H. L. (1990). Influence of metacognitive knowledge and aptitude on problem solving. Journal of Educational Psychology, 82(2), 306-314.

Tapola, A., Veermans, M., \& Niemivirta, M. (2013). Predictors and outcomes of situational interest during a science learning task. Instructional Science, 41, 1047-1064.

Vaino, K., Holbrook, J., \& Rannikmäe, M. (2012). Stimulating students' intrinsic motivation for learning chemistry through the use of context-based learning modules. Chemistry Education, Research, and Practice. https://doi.org/10.1039/ c2rp20045g

van Vorst, H., Dorschu, A., Fechner, S., Kauertz, A., \& Krabbe, H. \& Sumfleth, E. (2014). Charakterisierung und Strukturierung von Kontexten im naturwissenschaftlichen Unterricht Vorschlag einer theoretischen Modellierung [Characterization and structuring of contexts in science education - a suggested theoretical model]. Zeitschrift für Didaktik der Naturwissenschaften, 21(1), 29-39.

Walpuski, M., \& Ropohl, M. Sumflet, E. (2011). Students' knowledge about chemical reactions - development and analysis of standard-based test items. Chemical Education Research and Practice, 12(2), 174-183.

Walkington, C. A. (2013). Using adaptive learning technologies to personalize instruction to student interests: The impact of relevant contexts on performance and learning outcomes. Journal of Educational Psychology, 105(4), 932945. https://doi.org/10.1037/a0031882 